\title{
Estudos de Competitividade Turística - Comparativo do Modelo de Dwyer e Kim e do Estudo de Competitividade dos 65 Destinos Indutores do Brasil
}

\section{Touristic Competitiveness Studies - A Comparative of Dwyer and Kim's Model and the 65 Inductors Destinations Competitiveness Study of Brazil}

\author{
Thays Cristina Domareski Ruiz (T. C., DOMARESKI-RUIZ), \\ Gisah Moreira Akel (AKEL, G. M.) ${ }^{* *}$, \\ José Manoel Gonçalves Gândara (GÂNDARA, J. M. G.) ${ }^{* * *}$
}

\begin{abstract}
RESUMO - No presente artigo se teve como objetivo principal analisar as dimensões do Modelo de Competitividade de Dwyer e Kim (2003), e comparar com o proposto no Estudo de Competitividade dos 65 Destinos Indutores do Instituto Brasileiro de Turismo (FGV; MTUR; SEBRAE, 2014), e dessa forma, apresentar um panorama sobre quais dimensões estavam sendo avaliadas nos modelos. Foram abordados aspectos relativos à qualidade, marketing e sustentabilidade. Para este estudo foi realizada uma pesquisa bibliográfica e documental. Como principais resultados, verificou-se que o modelo de Dwyer e Kim se apresentou mais complexo e com análises mais específicas referentes à competitividade, porém ambos se remeteram às temáticas de qualidade, marketing e sustentabilidade.
\end{abstract}

Palavras-chave: Turismo; Competitividade; Marketing; Qualidade; Sustentabilidade.

ABSTRACT - The present paper aims to analyze the dimensions of Dwyer and Kim Competitiveness Model (2003), and to compare them with the Brazilian study of Competitiveness of the 65 inductors destinations of the Ministry of Tourism (FGV; MTUR; SEBRAE, 2014), and thus to present an overview of the dimensions that were been evaluated in the models. Aspects were addressed on quality, marketing and sustainability. For this study a bibliographic and documentary research was conducted. As main results, it was found that the model Dwyer and Kim (2003) appeared more

\footnotetext{
* Formação: Graduação em Turismo pela Universidade Estadual do Oeste do Paraná (UNIOESTE). Mestrado em Turismo e Hotelaria pela Universidade do Vale do Itajaí (UNIVALI). Doutoranda em Geografia pela Universidade Federal do Paraná (UFPR). Endereço físico para correspondência: Departamento de Turismo (UFPR). Rua Dr. Faivre, 405 - Ed. D. Pedro II, $3^{\circ}$ andar. CEP: 80060-140 Curitiba/PR - Brasil. E-mail: thaysdomareski@gmail.com

** Formação: Graduação em Turismo pela Universidade Federal do Paraná (UFPR), Mestrado em Turismo pela UVIGO (Espanha). Pós-graduanda MBA em Marketing pela Universidade Federal do Paraná. Endereço físico para correspondência: Departamento de Turismo (UFPR). Rua Dr. Faivre, 405 Ed. D. Pedro II, $3^{\circ}$ andar. CEP: 80060-140 - Curitiba/PR - Brasil. E-mail: gikakel@ gmail.com

*** Formação: Graduação em Turismo pela Universidade Federal do Paraná (UFPR), Mestrado em Gestão do Turismo pela SSCTS (Itália), Doutorado em Turismo e Desenvolvimento Sustentável pela ULPGC (Espanha). Pós-doutorados pelas Universidades de Málaga, Las Palmas de Gran Canaria, Valência, Vigo e Alicante (Espanha). Atividade profissional: professor e pesquisador do Departamento de Turismo, do Programa de Mestrado em Turismo da UFPR e do Programa de Mestrado e Doutorado em Geografia da UFPR. Endereço físico para correspondência: Departamento de Turismo (UFPR). Rua Dr. Faivre, 405 - Ed. D. Pedro II, $3^{\circ}$ andar. CEP: 80060-140 - Curitiba/PR - Brasil. E-mail: jmggandara@yahoo.com.br
} 
complex and with more specific analyzes relating to competitiveness, but both are forwarded to quality, marketing and sustainability issues.

Key words: Tourism; Competitiveness; Marketing; Quality; Sustainability. 


\section{INTRODUÇÃO}

O conceito de competitividade tem sido um referencial teórico prioritário na literatura dedicada à estratégia, tanto no âmbito empresarial ou industrial, quanto na economia internacional, ou de destinos turísticos (PORTER, 1989; MATEUS et al, 2005; FGV; MTUR; SEBRAE, 2014; DOMARESKI, 2011).

Neste contexto, o interesse em conhecer os determinantes da competitividade dos destinos turísticos e, acima de tudo, sobre a inclusão da sustentabilidade como uma estratégia de condicionamento variável, levou à existência de diferentes modelos conceituais (MAZARO; VARZIN, 2008).

A competitividade de destinos turísticos é um conceito multidimensional, que requer a superioridade em diversos aspectos para ser obtida em relação a seus concorrentes. É um critério dinâmico, e embora a noção de competitividade seja mais simples de se compreender, quando se tenta estudar e medir a competitividade entre os destinos turísticos, evidencia-se o quão difícil é defini-la (CROUCH; RITCHIE, 1999).

A discussão em torno do tema competitividade de destinos turísticos reforça o conceito multifacetado da competitividade (DWYER; KIM, 2003). Neste contexto de globalização e desenvolvimento, a competitividade pode ser entendida como a capacidade crescente de gerar negócios lucrativos nas atividades econômicas, de forma sustentável, superior à concorrência, onde os conceitos de planejamento e gestão seguem em paralelo para atingir o desenvolvimento.

Com consumidores cada vez mais informados e exigentes, para tornar-se competitivo mediante parâmetros de qualidade dos diversos elementos que compõem um destino turístico, exige desenvolver estratégias conjuntas e integradas entre os atores locais visando obter maior qualificação dos serviços, tanto na sua individualidade, quanto na avaliação do todo, do conjunto do destino turístico (GÂNDARA, 2004).

A competitividade de destinos turísticos é complexa, um conceito que combina vários elementos, que às vezes não é fácil de medir, onde para competir um destino precisa ter vantagens comparativas e competitivas, ou seja, deve ter uma grande variedade de produtos e recursos turísticos que devem ser geridos de forma eficiente e eficaz no médio e longo prazo (GÂNDARA et al, 2013). 
Dessa forma, se propõe um panorama comparativo entre o Modelo de Competitividade de Dwyer e Kim (2003) e o Estudo de Competitividade dos 65 Destinos Indutores (FGV; MTUR; SEBRAE, 2014), relacionando as temáticas de qualidade, marketing e sustentabilidade. A partir desta premissa, o estudo se caracteriza como exploratório através de uma pesquisa bibliográfica e documental, sendo que a análise e a validação dos resultados se deram segundo Laville e Dionne (1999), por emparelhamento com a discussão conceitual realizada anteriormente no marco teórico. O uso do emparelhamento justifica-se, uma vez que um pesquisador busque, a partir de uma abordagem teórica, compreender o fenômeno estudado. Contudo, é necessário que seja comprovada a associação entre teoria e realidade, garantindo a qualidade do estudo desenvolvido (KRIPPENDORFF, 1980; LAVILLE; DIONNE, 1999).

\section{COMPETITIVIDADE, QUALIDADE, MARKETING E SUSTENTABILIDADE DE DESTINOS TURÍSTICOS}

O emprego da competitividade como área de pesquisa relacionada ao turismo ainda pode ser considerado recente. Porém, o setor do turismo se afirma como importante fonte geradora de emprego e renda, o que garante uma dimensão diretamente relacionada à economia de um destino turístico (EMBRATUR, 2010). Toda a proposta de desenvolvimento da competitividade de destinos turísticos está focada na geração de emprego e renda e no intuito de promover o desenvolvimento econômico. A pesquisa acadêmica em turismo cresceu muito devido à ampliação do setor e à necessidade de se produzir material que dê subsídios para o desenvolvimento do mercado de serviços e viagens. O tema se torna cada vez mais representativo, devido à crescente oferta de destinos turísticos no mercado, o que faz a gestão dos destinos turísticos ter a necessidade de manter o foco no conceito da competitividade (HASSAN, 2000).

De fato, o que torna um destino turístico competitivo é a capacidade de seus gestores em aumentar os gastos dos turistas, atraindo cada vez mais visitantes, proporcionando-lhes satisfação e experiências memoráveis, enquanto melhora o bemestar dos residentes do destino, preservando-o para as futuras gerações (RITCHIE; CROUCH, 2003). No âmbito dos destinos turísticos, a vantagem competitiva é 
alcançada a partir do momento que um destino oferece uma experiência turística superior em relação a outro destino, considerando os turistas potenciais deste (DWYER; KIM, 2003; COSTA, 2005).

Os pesquisadores da área vêm desenvolvendo estudos que procuram compreender o momento do turismo, e ao mesmo tempo contribuir para o processo de gestão dos destinos turísticos. O novo contexto do turismo globalizado se caracteriza por uma situação onde a competitividade dos destinos turísticos é cada vez mais importante para aquelas economias que dependem diretamente da atividade turística (TABERNER, 2007).

Nos estudos de competitividade, as temáticas de qualidade, marketing e sustentabilidade sempre estão presentes. Assim, uma das mais importantes tarefas de qualquer organização que tenha o marketing do destino a seu encargo é coordenar as diversas partes, de forma a promover a cooperação e gerar experiências compatíveis e de qualidade para a valorização e sustentabilidade de um destino (BUHALIS, 2000). Neste contexto se faz necessário endossar a perspectiva da qualidade de um destino desde o viés objetivo compreendendo a avaliação técnica dos atributos do mesmo (ZEITHAML et al, 2003).

O marketing integrado possibilita um relacionamento eficaz com o mercado, procurando maximizar os benefícios do desenvolvimento turístico e minimizar os seus impactos negativos (KASTENHOLZ, 2004, 2006; MIDDLETON; HAWKINS, 1998). Assim, os gestores não somente devem enaltecer os valores agregados ofertados pela localidade, mas devem antever prováveis ameaças antes que estas concretizem problemas, ao passo que vislumbrem oportunidades para que de fato as mesmas possam ser aproveitadas favoravelmente (ANDRADES-CALDITO et al, 2013). Portanto, o emprego do marketing se torna imprescindível para a sustentabilidade dos destinos turísticos (GÂNDARA, 2001).

O setor do turismo é frequentemente considerado um setor estratégico com interesse em desenvolver-se de forma estruturada e sustentável, dinamizando outros setores econômicos e sociais. Entretanto, o desenvolvimento sustentável implica a definição de linhas orientadoras de planejamento para minimizar os efeitos negativos da atividade turística e a maximizar os seus benefícios (INSKEEP, 1991). 
Neste sentido, toda a discussão da sustentabilidade, em sua perspectiva global, se consolida como um dos temas centrais no debate do turismo como fenômeno complexo (IRVING; SANCHO, 2005). O desenvolvimento turístico sustentável só ocorrerá se houver ações que estimulem a participação dos atores sociais nas decisões propostas para o desenvolvimento das localidades turísticas (KRIPPENDORF, 1977).

O turismo constitui-se em uma oportunidade para o desenvolvimento sustentável à medida que promove a utilização de recursos naturais e culturais, dinamiza e integra setores da economia local e regional (SANTOS; TEIXEIRA, 2008). Assim, o turismo é um fenômeno socioeconômico que atua tanto como força motriz do progresso econômico como força social, portanto, deve considerado em um contexto mais amplo (DAVIDSON, 2001).

Neste contexto de planejamento e desenvolvimento sustentável, um destino turístico passa a agregar um diferencial de qualidade e, o turista, passa a ocupar o lugar de "agente de transformação" na escolha de um destino. Com essa estratégia, a percepção do turista e de seu papel na seleção de destinos social e ambientalmente desejáveis, vem exigindo do trade turístico uma nova postura, que privilegia a competitividade, mas também as especificidades das escolhas do turista e a qualidade do destino. De fato, pensar em sustentabilidade no turismo implica em idealismo e visão estratégica de longo prazo, mas também pragmatismo, a partir de experiências capazes de transformar utopia em possibilidade, discurso em prática cotidiana (IRVING; SANCHO, 2005).

Atrelada ao conceito de qualidade está a questão da qualidade percebida, diretamente relacionada às experiências do indivíduo (ZEITHAML et al, 2003) e que no contexto de um destino equivale ao somatório de produtos e serviços oferecidos por diversas unidades de negócio para que o turista forme uma única avaliação global do mesmo (BUHALIS, 2000). Ante este panorama, as necessidades do consumidor e os objetivos do destino tornam-se cada vez mais semelhantes e inseparáveis, ampliando o espectro de compromisso para/com o anseio do cliente e não só a responsabilidade da gestão pública do destino, senão também de cada uma das empresas atuantes neste território (GO; GOVERS, 2000).

Em concordância com as temáticas abordadas até o momento, é importante ter presente que numa estratégia de marketing se deve considerar uma série de outros 
aspectos tais como a qualidade do destino, sua distribuição, sua comunicação e o preço, para dessa maneira construir um destino turístico competitivo (GÂNDARA et al, 2007).

A partir disso, a sustentabilidade dos destinos turísticos deve ser levada em consideração no desenvolvimento e gestão dos próprios destinos, para que as gerações futuras possam usufruir de um destino de qualidade (GÂNDARA, 2001; SOUZA, 2005).

\section{MODELO DE COMPETITIVIDADE DE DWYER E KIM}

Dwyer e Kim (2003) desenvolveram um sistema de indicadores de competitividade de destinos turísticos que apresenta um conjunto de elementos integrados entre si, que eles consideraram de efetiva importância para a definição da competitividade de um destino turístico.

O modelo proposto por Dwyer e Kim (2003) é considerado sistêmico e contempla quatro determinantes principais dispostos em quadrantes-chave, que são: recursos, gestão do destino turístico, condições situacionais e demanda. Estes determinantes se integram a fim de atingir a competitividade turística. Porém, o modelo apresenta como objetivo maior a prosperidade socioeconômica do destino turístico e o aumento da qualidade de vida de sua população, assim representam o resultado da competitividade do destino (DWYER; KIM, 2003).

No Modelo de Dwyer e Kim, se relacionam 7 macrodimensões, 28 dimensões e 150 variáveis/indicadores, onde ele não só identifica, mas também insere aspectos relacionados à quantificação, qualidade e eficiência, o que não é evidenciado no estudo brasileiro de competitividade. Dessa forma, seguem abaixo os indicadores devidamente separados pelos determinantes apontados no Modelo de Dwyer e Kim (2003):

QUADRO 1 - INDICADORES DO MODELO DE DWYER E KIM, 2003.

\begin{tabular}{|l|l|l|}
\hline MACRO DIMENSÕES & DIMENSÕES & \multicolumn{1}{c|}{ INDICADORES } \\
\hline \multirow{4}{*}{$\begin{array}{c}\text { Infraestrutura } \\
\text { Turística }\end{array}$} & Qualidade e variedade de hospedagem \\
\cline { 3 - 3 } & & Eficiência e qualidade dos aeroportos \\
\cline { 3 - 3 } & & Informação Turística \\
& & Eficiência e qualidade do transporte local \\
& & Acessibilidade às áreas naturais \\
\cline { 3 - 3 } & & Espaço para convenções e eventos (Capacidade e Qualidade) \\
\cline { 3 - 3 } & & Qualidade e Variedade de serviços de alimentação \\
\hline
\end{tabular}

Continua... 
Continuação...

\begin{tabular}{|c|c|c|}
\hline & & \\
\hline & & Baseados na água \\
\hline & & Baseados na natureza \\
\hline & Série de & Atividades de aventura \\
\hline & atividades & Instalações recreativas \\
\hline & & Instalações esportivas \\
\hline & & Variedade de artigos de compras \\
\hline & & Qualidade das instalações comerciais \\
\hline & Shopping & Qualidade dos artigos de compras \\
\hline Recursos criados & & Relação qualidade/preço dos artigos de compras \\
\hline & & Diversidade de experiências de compras \\
\hline & & Diversão / Parques temáticos \\
\hline & Entretenimento & Qualidade e Variedade dos entretenimentos \\
\hline & & Vida noturna \\
\hline & $\begin{array}{l}\text { Eventos especiais } \\
\text { /festivais }\end{array}$ & Eventos especiais e festivais \\
\hline & & $\begin{array}{l}\text { Adequação da infraestrutura para satisfazer as necessidades } \\
\text { dos visitantes }\end{array}$ \\
\hline & & Saúde - centros médicos para os turistas \\
\hline & & Instituições financeiras e câmbio \\
\hline & Infraestrutura & Sistema de telecomunicações para o turista \\
\hline & & Segurança para os turistas \\
\hline & & Sistema de transporte local \\
\hline & & Eliminação de resíduos \\
\hline & & Fornecimento de energia elétrica \\
\hline & & $\begin{array}{l}\text { Empresas de hotelaria e turismo que têm bem definidos os } \\
\text { padrões de funcionamento de prestação de serviços }\end{array}$ \\
\hline & Qualidade dos & $\begin{array}{l}\text { Empresas com sistema para garantir ou monitorar a satisfação } \\
\text { do visitante }\end{array}$ \\
\hline & Serviços & Satisfação do visitante com qualidade de serviço \\
\hline & & Apreciação da indústria com a qualidade do serviço \\
\hline Fatores de Apoio & & $\begin{array}{l}\text { Desenvolvimento de programas de capacitação e melhora na } \\
\text { qualidade do serviço }\end{array}$ \\
\hline & & Velocidade / atrasos / imigração \\
\hline & & Atitudes dos funcionários de imigração \\
\hline & & Distância / Tempo de voo dos destinos emissores chave \\
\hline & & Voos diretos e indiretos para o destino \\
\hline & Acessibilidade ao & Custo / Facilidade para a obtenção de visto \\
\hline & Destino & Facilidade de combinação de viagens com outros destinos \\
\hline & & Frequência e capacidade do transporte de acesso ao destino \\
\hline & & Cordialidade dos residentes com os turistas \\
\hline & Hospitalidade & $\begin{array}{l}\text { Existência de programas de desenvolvimento da hospitalidade } \\
\text { para os residentes }\end{array}$ \\
\hline & & Apoio dos residentes ao turismo local \\
\hline & & Facilidade de comunicação entre turistas e residentes \\
\hline & & $\begin{array}{l}\text { Relações comerciais com os principais mercados emissores de } \\
\text { turistas }\end{array}$ \\
\hline & Relações de & $\begin{array}{l}\text { Relações esportivas com os principais mercados emissores de } \\
\text { turistas }\end{array}$ \\
\hline & Mercado & $\begin{array}{l}\text { Laços étnicos com os principais mercados emissores de } \\
\text { turistas } \\
\text { Laços religiosos com os principais mercados emissores de } \\
\text { turistas }\end{array}$ \\
\hline & & Extensão do investimento estrangeiro no turismo local \\
\hline
\end{tabular}

Continua... 
Continuação...

\begin{tabular}{|c|c|c|}
\hline \multirow{12}{*}{ Recursos Dotados } & \multirow{7}{*}{ Naturais } & \\
\hline & & Clima confortável para o turismo \\
\hline & & Saneamento/Limpeza \\
\hline & & Maravilhas Naturais \\
\hline & & Flora e Fauna \\
\hline & & Natureza virgem \\
\hline & & Parques naturais / Reservas naturais \\
\hline & & Sítios de patrimônio histórico cultural e museus \\
\hline & & Características artísticas e arquitetônicas \\
\hline & & Artes tradicionais \\
\hline & Herdados & Variedade gastronômica \\
\hline & & Povos populares \\
\hline & & $\begin{array}{l}\mathrm{OMT}^{1} \text { atua como órgão coordenador para as organizações de } \\
\text { turismo, público e privada }\end{array}$ \\
\hline & & $\begin{array}{l}\text { OMT representa efetivamente as opiniões de todos os agentes } \\
\text { de turismo no desenvolvimento do turismo }\end{array}$ \\
\hline & Organização & $\begin{array}{l}\text { OMT serve de ligação entre o setor privado e as políticas } \\
\text { públicas, planejando e desenvolvendo o turismo }\end{array}$ \\
\hline & & $\begin{array}{l}\text { OMT proporciona informações estatísticas como parte das } \\
\text { políticas públicas, planejando e desenvolvendo o setor }\end{array}$ \\
\hline & & $\begin{array}{l}\begin{array}{l}\text { OMT monitora e avalia a natureza } \\
\text { desenvolvimento de turismo }\end{array} \\
\text { des tipos de }\end{array}$ \\
\hline & & Reputação da OMT \\
\hline & & Eficácia no posicionamento do destino \\
\hline & & Força / Clareza da imagem do destino \\
\hline & & $\begin{array}{l}\begin{array}{l}\text { Supervisão eficaz das atividades de comercialização dos } \\
\text { destinos }\end{array} \\
\end{array}$ \\
\hline & Marketing & Efetivos pacotes de experiência do destino \\
\hline & & Vínculo entre o destino turístico e o trade \\
\hline & & OMT identifica os mercadores emissores e promissores \\
\hline & & $\begin{array}{l}\text { OMT proporciona alianças estratégicas entre outras } \\
\text { instituições }\end{array}$ \\
\hline Coctõodo Dectine & & $\begin{array}{l}\text { Marketing do destino é baseado nos conhecimentos dos } \\
\text { produtos concorrentes }\end{array}$ \\
\hline Gestao do Destimo & & $\begin{array}{l}\text { Ajustes entre os produtos do destino e as preferências dos } \\
\text { visitantes }\end{array}$ \\
\hline & & $\begin{array}{l}\text { Existência da visão de longo prazo para o desenvolvimento do } \\
\text { turismo }\end{array}$ \\
\hline & & Visão do destino reflete os valores dos residentes \\
\hline & & $\begin{array}{l}\text { A visão do destino reflete os valores dos interessados no } \\
\text { turismo }\end{array}$ \\
\hline & Políticas & $\begin{array}{l}\text { A política pública está de acordo com a visão oficial do } \\
\text { destino }\end{array}$ \\
\hline & $\begin{array}{c}\text { Planejamento } \\
\text { Desenvolvimento }\end{array}$ & $\begin{array}{l}\text { O planejamento e o desenvolvimento estão de acordo com a } \\
\text { visão do turismo }\end{array}$ \\
\hline & & $\begin{array}{l}\text { O desenvolvimento do turismo se integra ao desenvolvimento } \\
\text { industrial geral }\end{array}$ \\
\hline & & $\begin{array}{l}\text { O desenvolvimento do turismo responde às necessidades dos } \\
\text { turistas }\end{array}$ \\
\hline & & $\begin{array}{l}\text { Medida em que os resultados da investigação são integrados } \\
\text { em planejamento turístico e desenvolvimento }\end{array}$ \\
\hline & & Inventário \\
\hline & & Identificação dos seus maiores concorrentes e seus produtos \\
\hline & & Apoio da comunidade em eventos especiais \\
\hline
\end{tabular}

${ }^{1}$ OMT - Organização Mundial do Turismo. 
Continuação...

\begin{tabular}{|c|c|c|}
\hline & \multirow{4}{*}{$\begin{array}{l}\text { Desenvolvimento } \\
\text { de Recursos } \\
\text { Humanos }\end{array}$} & 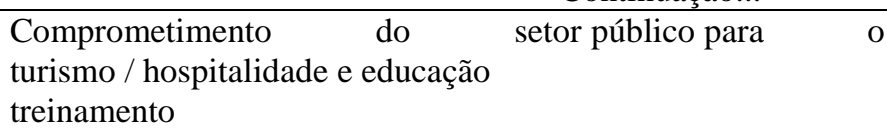 \\
\hline & & $\begin{array}{l}\text { Comprometimento do } \quad \text { setor privado para } \\
\text { turismo / hospitalidade e educação } \\
\text { treinamento }\end{array}$ \\
\hline & & $\begin{array}{l}\text { Formação / educação sensível às } \\
\text { necessidades do visitante }\end{array}$ \\
\hline & & $\begin{array}{l}\text { Qualidade dos programas de } \text { turismo / hospitalidade / } \\
\text { treinamento de formação }\end{array}$ \\
\hline & \multirow{4}{*}{ Gestão Ambiental } & $\begin{array}{l}\text { O reconhecimento do setor público da importância do } \\
\text { desenvolvimento do turismo sustentável }\end{array}$ \\
\hline & & $\begin{array}{l}\text { O reconhecimento do setor privado da importância do } \\
\text { desenvolvimento do turismo sustentável }\end{array}$ \\
\hline & & $\begin{array}{l}\text { Existência de leis e regulamentos que protegem o meio } \\
\text { ambiente e o patrimônio }\end{array}$ \\
\hline & & Pesquisa e monitoramento dos impactos ambientais no turismo \\
\hline \multirow{29}{*}{ Condição Situacional } & \multirow{9}{*}{$\begin{array}{l}\text { Entorno } \\
\text { Competitivo } \\
\text { (micro) }\end{array}$} & Meio empresarial nacional no destino \\
\hline & & Gestão das capacidades das empresas de turismo \\
\hline & & $\begin{array}{l}\text { Nível de rivalidade competitiva entre as empresas (turismo } \\
\text { interno) }\end{array}$ \\
\hline & & Nível de cooperação entre as empresas do destino \\
\hline & & $\begin{array}{l}\text { Vínculo entre as empresas de turismo e hotelaria e de outras } \\
\text { empresas }\end{array}$ \\
\hline & & Qualidades empreendedoras dos agentes de turismo local \\
\hline & & Acesso ao capital de risco \\
\hline & & Ética entre as empresas de turismo \\
\hline & & $\begin{array}{l}\text { Empresas utilizam a tecnologia para garantir a vantagem } \\
\text { competitiva }\end{array}$ \\
\hline & \multirow{4}{*}{$\begin{array}{l}\text { Localização do } \\
\text { Destino }\end{array}$} & Exotismo da localização \\
\hline & & Proximidade de outros destinos \\
\hline & & Distância do maior mercado emissor \\
\hline & & Tempo de viagem a partir do maior mercado emissor \\
\hline & \multirow{8}{*}{$\begin{array}{l}\text { Entorno Global } \\
\quad(\text { macro })\end{array}$} & Contexto global dos negócios \\
\hline & & Estabilidade política \\
\hline & & Meio legal e regulatório \\
\hline & & Políticas governamentais para o desenvolvimento do turismo \\
\hline & & Condições econômicas dos mercados de origem \\
\hline & & Meio sociocultural \\
\hline & & Investimentos para o desenvolvimento do turismo \\
\hline & & Mudanças tecnológicas \\
\hline & \multirow{6}{*}{$\begin{array}{l}\text { Preço } \\
\text { Competitivo }\end{array}$} & Relação qualidade-preço do destino turístico \\
\hline & & Taxas de câmbio \\
\hline & & $\begin{array}{l}\text { Preços das passagens de avião dos principais mercados de } \\
\text { origem }\end{array}$ \\
\hline & & Preços das hospedagens \\
\hline & & Preços dos pacotes turísticos \\
\hline & & Preço da viagem em relação aos destinos concorrentes \\
\hline & \multirow[b]{2}{*}{ Segurança } & Nível de segurança do turista no destino \\
\hline & & Incidência de crime contra o turista no destino \\
\hline
\end{tabular}

Continua... 
Continuação...

\begin{tabular}{|c|c|c|}
\hline \multirow{3}{*}{\multicolumn{2}{|c|}{ Fatores da Demanda }} & Consciência do destino \\
\hline & & Percepção do destino \\
\hline & & Preferência do destino \\
\hline \multirow{34}{*}{$\begin{array}{c}\text { Indicadores de Rendimento } \\
\text { de Mercado }\end{array}$} & \multirow{11}{*}{$\begin{array}{l}\text { Estatísticas dos } \\
\text { visitantes }\end{array}$} & Número de visitantes estrangeiros \\
\hline & & Crescimento da taxa de visitantes estrangeiros \\
\hline & & Cota dos mercados do destino - mundial, regional \\
\hline & & Mudanças nas cotas de mercado \\
\hline & & Média de permanência \\
\hline & & Taxa de retorno ao destino \\
\hline & & Gastos dos visitantes estrangeiros \\
\hline & & Crescimento da taxa de gastos dos visitantes estrangeiros \\
\hline & & $\begin{array}{l}\text { Porcentagem dos gastos totais no destino em turismo - } \\
\text { mundial, regional }\end{array}$ \\
\hline & & Cambio nas porcentagens de gastos \\
\hline & & 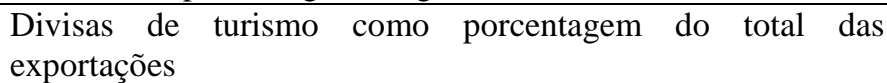 \\
\hline & \multirow{5}{*}{$\begin{array}{c}\text { Contribuição do } \\
\text { Turismo para } \\
\text { Economia }\end{array}$} & Contribuição do turismo em valor agregado \\
\hline & & Turismo interno \\
\hline & & Turismo internacional \\
\hline & & $\begin{array}{l}\text { Contribuição do turismo em empregos (números absolutos; } \\
\text { porcentagem de emprego total e a taxa de crescimento }\end{array}$ \\
\hline & & Produtividade dos setores na indústria do turismo \\
\hline & \multirow{3}{*}{$\begin{array}{l}\text { Prosperidade } \\
\text { Econômica }\end{array}$} & Total de níveis de emprego \\
\hline & & Taxa de crescimento econômico \\
\hline & & Renda per capita \\
\hline & \multirow{3}{*}{$\begin{array}{l}\text { Investimento em } \\
\text { Turismo }\end{array}$} & Investimento nacional no turismo \\
\hline & & Investimento estrangeiro no turismo \\
\hline & & $\begin{array}{l}\text { Investimento no turismo como porcentagem total do } \\
\text { investimento na indústria (tendência) }\end{array}$ \\
\hline & \multirow{3}{*}{$\begin{array}{c}\text { Índice de } \\
\text { Competitividade } \\
\text { de Preços }\end{array}$} & Índice agregado pela competitividade de preços \\
\hline & & Por propósito de viagem \\
\hline & & Por setor de turismo \\
\hline & \multirow{9}{*}{$\begin{array}{c}\text { Apoio } \\
\text { Governamental } \\
\text { ao turismo }\end{array}$} & Orçamento do Ministério do Turismo \\
\hline & & Orçamento da OMT \\
\hline & & $\begin{array}{l}\text { Gasto com o marketing do destino (comparação com os } \\
\text { concorrentes) }\end{array}$ \\
\hline & & Apoio à indústria de transportes \\
\hline & & Programas industriais pelo acesso da indústria do turismo \\
\hline & & Benefícios Fiscais \\
\hline & & Subsídios da indústria \\
\hline & & Assistência na comercialização de exportações \\
\hline & & $\begin{array}{l}\text { Habilidades profissionais de educação - Treinamento para o } \\
\text { turismo }\end{array}$ \\
\hline
\end{tabular}

Fonte: Dwyer e Kim, 2003.

Os principais limitantes da aplicação dos modelos de competitividade de destinos turísticos são que alguns destinos não possuem dados suficientes para a aplicação, e muito menos indicadores que possam embasar tal pesquisa de forma concreta. No caso específico do modelo de Dwyer e Kim (2003) são aplicados 150 indicadores, o que exige tempo e disponibilidade de dados para a aplicação do modelo. É importante ressaltar que os próprios autores relacionam uma série de indicadores para 
medir a competitividade, embora reconheçam que eles não são os únicos que poderiam ter formado a base da pesquisa. A proposta de análise é ampla e abrangente, sendo de efetiva importância para a análise de vários fatores que unidos garantam a competitividade de um destino turístico (DWYER; KIM, 2003).

\section{ESTUDO DE COMPETITIVIDADE DOS 65 DESTINOS INDUTORES}

O Estudo de Competitividade dos 65 Destinos Indutores é um documento brasileiro que foi elaborado pelo Ministério do Turismo - MTur, pela Fundação Getúlio Vargas - FGV e pelo Serviço Brasileiro de Apoio à Micro e Pequenas Empresas SEBRAE, e a partir de um diagnóstico detalhado das condições e recursos definiu os 65 destinos turísticos brasileiros que determinam e direcionam o turismo no país. Este estudo faz parte do Plano Nacional de Turismo e do Programa de Regionalização do Turismo - Roteiros do Brasil, proposto pelo Ministério do Turismo (FGV; MTUR; SEBRAE, 2014). O objetivo central deste estudo foi realizar um diagnóstico detalhado da realidade dos destinos indutores avaliados, a fim de colocar em perspectiva os níveis de competitividade turística de cada um, e permitir que gradualmente possam, com base nos princípios de sustentabilidade, oferecer produtos e serviços de melhor qualidade a turistas nacionais e estrangeiros (FGV; MTUR; SEBRAE, 2014).

Foram selecionados 65 destinos turísticos e posteriormente foram definidas 13 dimensões a serem avaliadas e estudadas em cada destino indutor: infraestrutura geral, acesso, serviços e equipamentos turísticos, atrativos turísticos, marketing, políticas públicas, cooperação regional, monitoramento, economia local, capacidade empresarial, aspectos sociais, aspectos ambientais e aspectos culturais. Em um maior nível de detalhamento, cada dimensão foi desmembrada em diversas variáveis, de forma a possibilitar a adoção eficaz de medidas. O intuito é de corrigir eventuais deficiências em setores específicos (FGV; MTUR; SEBRAE, 2014), onde o principal critério de seleção foi a capacidade de desenvolvimento turístico destas cidades e seu entorno.

Para tanto, a equipe da FGV realizou um mapeamento minucioso das condições em que se encontravam os 65 municípios estudados, e propuseram cinco macro dimensões de análise, dentre elas: infraestrutura, turismo, políticas públicas, economia e sustentabilidade, subdivididas em treze dimensões. Para mensurá-las foram 
desenvolvidas escalas quantitativas a partir de uma mescla de variáveis objetivas e subjetivas (FGV; MTUR; SEBRAE, 2014) conforme se apresenta no quadro 2.

A escala utilizada no Estudo de Competitividade dos 65 Destinos Indutores foi configurada de 1 a 100 para mensuração dos quesitos em análise. Resumindo, o $1^{\circ}$ nível (0 a 20) representa deficiências no destino, em relação ao elemento em análise, o $2^{\circ}$ nível (21 a 40) significa uma situação melhor que a anterior, mas ainda inadequada para a competitividade de um destino, o $3^{\circ}$ nível (41 a 60), configura situação regularmente satisfatória, o $4^{\circ}$ nível (61 a 80) revela a existência de condições adequadas para o desenvolvimento do turismo e o $5^{\circ}$ nível (81 a 100) representa o melhor desempenho que um destino pode alcançar referente ao quesito mensurado. Evidencia-se que para esta pesquisa o $4^{\circ}$ nível representa o padrão mínimo de qualidade para a dimensão avaliada no destino (FGV; MTUR; SEBRAE, 2014).

QUADRO 2- DIMENSÕES E VARIÁVEIS DO ESTUDO DE COMPETITIVIDADE DOS 65 DESTINOS INDUTORES

\begin{tabular}{|c|c|c|}
\hline Macrodimensões & Dimensões & Variáveis \\
\hline \multirow[b]{2}{*}{ Infraestrutura } & $\begin{array}{c}\text { Infraestrutura } \\
\text { Geral }\end{array}$ & $\begin{array}{l}\text { Capacidade de atendimento médico ao turista; } \\
\text { Fornecimento de energia; } \\
\text { Serviço de proteção ao turista; } \\
\text { Estrutura urbana nas áreas turísticas; }\end{array}$ \\
\hline & Acesso & $\begin{array}{l}\text { Acesso aéreo; } \\
\text { Acesso rodoviário; } \\
\text { Acesso aquaviário; } \\
\text { Acesso ferroviário; } \\
\text { Sistema de transporte no destino; } \\
\text { Proximidade de grandes centros emissivos de turistas; }\end{array}$ \\
\hline \multirow{3}{*}{ Turismo } & $\begin{array}{c}\text { Serviços e } \\
\text { Equipamentos } \\
\text { Turísticos }\end{array}$ & $\begin{array}{l}\text { Sinalização Turística; } \\
\text { Centro de atendimento ao turista; } \\
\text { Espaço para eventos; } \\
\text { Capacidade dos meios de hospedagem; } \\
\text { Capacidade do turismo receptivo; } \\
\text { Estrutura de qualificação para o turismo; } \\
\text { Capacidade dos Restaurantes; }\end{array}$ \\
\hline & $\begin{array}{l}\text { Atrativos } \\
\text { Turísticos }\end{array}$ & $\begin{array}{l}\text { Atrativos Naturais; } \\
\text { Atrativos Culturais; } \\
\text { Eventos programados; } \\
\text { Realizações técnicas, científicas e artísticas; }\end{array}$ \\
\hline & Marketing & $\begin{array}{l}\text { Plano de marketing; } \\
\text { Participação em feiras e eventos; } \\
\text { Promoção do destino; } \\
\text { Página do destino na internet; }\end{array}$ \\
\hline Política & $\begin{array}{l}\text { Políticas } \\
\text { Públicas }\end{array}$ & $\begin{array}{l}\text { Estrutura municipal para apoio ao turismo; } \\
\text { Grau de cooperação com o governo estadual; } \\
\text { Grau de cooperação com o governo federal; } \\
\text { Planejamento para a cidade e para a atividade turística; } \\
\text { Grau de cooperação público-privada; }\end{array}$ \\
\hline
\end{tabular}


Continuação...

\begin{tabular}{|c|c|c|}
\hline & $\begin{array}{c}\text { Cooperação } \\
\text { Regional }\end{array}$ & $\begin{array}{l}\text { Governança; } \\
\text { Projetos de cooperação regional; } \\
\text { Planejamento turístico regional; } \\
\text { Roteirização; } \\
\text { Promoção e apoio à comercialização de forma integrada; }\end{array}$ \\
\hline & Monitoramento & $\begin{array}{l}\text { Pesquisas de demanda; } \\
\text { Pesquisas de oferta; } \\
\text { Sistema de estatísticas do turismo; } \\
\text { Medição dos impactos da atividade turística; } \\
\text { Setor específico de estudos e pesquisas; }\end{array}$ \\
\hline \multirow[b]{2}{*}{ Economia } & Economia Local & $\begin{array}{l}\text { Aspectos da economia local; } \\
\text { Infraestrutura de comunicação; } \\
\text { Infraestrutura e facilidades para negócios; } \\
\text { Empreendimentos ou eventos alavancadores; }\end{array}$ \\
\hline & $\begin{array}{l}\text { Capacidade } \\
\text { Empresarial }\end{array}$ & $\begin{array}{l}\text { Capacidade de qualificação e aproveitamento da pessoa local; } \\
\text { Presença de grupos nacionais e internacionais do setor de } \\
\text { turismo; } \\
\text { Concorrências e barreiras de entrada; } \\
\text { Número de empresas de grande porte, filiais e/ou subsidiárias. }\end{array}$ \\
\hline \multirow{3}{*}{ Sustentabilidade } & Aspectos Sociais & $\begin{array}{l}\text { Acesso à educação; } \\
\text { Empregos gerados pelo turismo; } \\
\text { Política de enfrentamento e prevenção à exploração sexual } \\
\text { infanto-juvenil; } \\
\text { Uso de atrativos e equipamentos turísticos pela população; } \\
\text { Cidadania, sensibilização e participação na atividade turística; }\end{array}$ \\
\hline & $\begin{array}{l}\text { Aspectos } \\
\text { Ambientais }\end{array}$ & $\begin{array}{l}\text { Estrutura e legislação municipal do meio ambiente; } \\
\text { Atividades em curso potencialmente poluidoras; } \\
\text { Rede pública de distribuição de água; } \\
\text { Rede pública de coleta e tratamento de esgoto; } \\
\text { Coleta e destinação pública de resíduos; } \\
\text { Unidades de conservação no território municipal. }\end{array}$ \\
\hline & $\begin{array}{l}\text { Aspectos } \\
\text { Culturais }\end{array}$ & $\begin{array}{l}\text { Produção cultural associada ao turismo; } \\
\text { Patrimônio histórico e cultural; } \\
\text { Estrutura municipal de apoio à cultura; }\end{array}$ \\
\hline
\end{tabular}

Fonte: Fgv; Mtur; Sebrae, 2014.

O estudo do Ministério do Turismo tem como uma de suas expectativas que com o aumento da competitividade os destinos sejam capazes de distribuir os fluxos de turistas recebidos, assim como dinamizar as economias do território em que se encontram inseridos (FGV; MTUR; SEBRAE, 2014). Dessa forma, pressupõe-se que o aumento da competitividade do destino esteja relacionado em um primeiro momento com o seu desenvolvimento econômico e, em um segundo momento, com o desenvolvimento de sua região (VIEIRA, 2013). 


\section{PANORAMA COMPARATIVO DE ANÁliSE DOS MODELOS DE COMPETITIVIDADE}

Verificou-se que a literatura da área de turismo tem apresentado vários estudos sobre competitividade de destinos turísticos (CROUCH; RITCHIE, 1999; DWYER; KIM，2003; HASSAN, 2000, HU; WALL，2005; MIHALIC，2000; RITCHIE; CROUCH, 2000, 2003; ALONSO FERRERAS, 2010; CHIM-MIKI; GÂNDARA; MEDINA MUÑOZ, 2012). Dessa forma, pode-se afirmar que a competitividade está relacionada aos aspectos de marketing, qualidade e sustentabilidade do destino turístico, reassegurando o processo de planejamento do destino a fim de possibilitar um destino competitivo. Neste instrumento, a gestão e o marketing turístico devem atuar como ferramentas e facilitadores para atingir objetivos estratégicos que beneficiem os stakeholders do destino, e consequentemente o destino turístico como um todo (BUHALIS, 2000; GÂNDARA et al, 2013).

Comparando-se os dois modelos, observa-se que a classificação do Modelo de Dwyer e Kim é mais detalhada, se desmembra em 7 macro dimensões e em 28 dimensões que geram 150 indicadores, o que proporciona um estudo mais completo e complexo. Enquanto que o Estudo de Competitividade dos 65 Destinos Indutores não detalha tanto, de 13 dimensões em 61 indicadores/variáveis, porém ambos classificam níveis de competitividade nos destinos turísticos.

O que pode ser observado no quadro relacionado ao Modelo de Dwyer e Kim (2003), são os itens que não apresentam nenhuma relação aos indicadores do Estudo de Competitividade dos 65 destinos indutores, dos 150 indicadores 84 não estão relacionados ao estudo brasileiro.

QUADRO 3 - COMPARATIVO DO MODELO DE DWYER E KIM, (2003) E O ESTUDO DOS 65 DESTINOS INDUTORES (FGV; MTUR; SEBRAE, 2014).

\begin{tabular}{|c|c|c|}
\hline DIMENSÕES & & INDICADORES/VARIÁVEIS \\
\hline \multirow{8}{*}{ Recursos criados } & \multirow{4}{*}{$\begin{array}{c}\text { Infraestrutura } \\
\text { Turística }\end{array}$} & Qualidade e variedade de hospedagem \\
\hline & & Eficiência e qualidade dos aeroportos \\
\hline & & Eficiência e qualidade do transporte local \\
\hline & & Qualidade e variedade de serviços de alimentação \\
\hline & \multirow{3}{*}{ Shopping } & Qualidade das instalações comerciais \\
\hline & & Qualidade dos artigos de compras \\
\hline & & Relação qualidade /preço dos artigos de compra \\
\hline & Entretenimento & Qualidade e variedade dos entretenimentos \\
\hline
\end{tabular}

Continua... 
Continuação...

\begin{tabular}{|c|c|c|}
\hline \multirow{21}{*}{ Fatores de Apoio } & Infraestrutura & $\begin{array}{l}\text { Adequação da infraestrutura para satisfazer as necessidades dos } \\
\text { visitantes }\end{array}$ \\
\hline & \multirow{6}{*}{$\begin{array}{l}\text { Qualidade dos } \\
\text { Serviços }\end{array}$} & $\begin{array}{l}\text { Empresas de hotelaria e turismo que têm bem definidos os } \\
\text { padrões de funcionamento de prestação de serviços }\end{array}$ \\
\hline & & $\begin{array}{l}\text { Empresas com sistema para garantir ou monitorar a satisfação } \\
\text { do visitante }\end{array}$ \\
\hline & & Satisfação do visitante com qualidade de serviço \\
\hline & & Apreciação da indústria com a qualidade do serviço \\
\hline & & Velocidade / atrasos / imigração \\
\hline & & Atitudes dos funcionários de imigração \\
\hline & \multirow{5}{*}{$\begin{array}{l}\text { Acessibilidade ao } \\
\text { Destino }\end{array}$} & Distância / Tempo de voo dos destinos emissores chave \\
\hline & & Voos diretos e indiretos para o destino \\
\hline & & Custo / Facilidade para a obtenção de visto \\
\hline & & Facilidade de combinação de viagens com outros destinos \\
\hline & & Frequência e capacidade do transporte de acesso ao destino \\
\hline & \multirow{4}{*}{ Hospitalidade } & Cordialidade dos residentes com os turistas \\
\hline & & $\begin{array}{l}\text { Existência de programas de desenvolvimento da hospitalidade } \\
\text { para os residentes }\end{array}$ \\
\hline & & Apoio dos residentes ao turismo local \\
\hline & & Facilidade de comunicação entre turistas e residentes \\
\hline & \multirow{5}{*}{$\begin{array}{l}\text { Relações de } \\
\text { Mercado }\end{array}$} & $\begin{array}{l}\text { Relações comerciais com os principais mercados emissores de } \\
\text { turistas }\end{array}$ \\
\hline & & $\begin{array}{l}\text { Relações esportivas com os principais mercados emissores de } \\
\text { turistas }\end{array}$ \\
\hline & & Laços étnicos com os principais mercados emissores de turistas \\
\hline & & $\begin{array}{l}\text { Laços religiosos com os principais mercados emissores de } \\
\text { turistas }\end{array}$ \\
\hline & & Extensão do investimento estrangeiro no turismo local \\
\hline \multirow{18}{*}{ Recursos Dotados } & Naturais & Clima confortável para o turismo \\
\hline & \multirow{3}{*}{ Herdados } & Artes tradicionais \\
\hline & & Variedade gastronômica \\
\hline & & Povos populares (villas) \\
\hline & \multirow{5}{*}{ Marketing } & Eficácia no posicionamento do destino \\
\hline & & Força / Clareza da imagem do destino \\
\hline & & $\begin{array}{l}\text { Supervisão eficaz das atividades de comercialização dos } \\
\text { destinos }\end{array}$ \\
\hline & & Efetivos pacotes de experiência do destino \\
\hline & & $\begin{array}{l}\text { Ajustes entre os produtos do destino e as preferências dos } \\
\text { visitantes }\end{array}$ \\
\hline & \multirow{8}{*}{$\begin{array}{c}\text { Políticas } \\
\text { Planejamento } \\
\text { Desenvolvimento }\end{array}$} & $\begin{array}{l}\text { Existência da visão de longo prazo para o desenvolvimento do } \\
\text { turismo }\end{array}$ \\
\hline & & Visão do destino refletem os valores dos residentes \\
\hline & & A visão do destino reflete os valores dos interessados no turismo \\
\hline & & A política pública está de acordo com a visão oficial do destino \\
\hline & & $\begin{array}{l}\text { O planejamento e o desenvolvimento estão de acordo com a } \\
\text { visão do turismo }\end{array}$ \\
\hline & & $\begin{array}{l}\text { O desenvolvimento do turismo se integra ao desenvolvimento } \\
\text { industrial geral }\end{array}$ \\
\hline & & $\begin{array}{l}\text { O desenvolvimento do turismo responde às necessidades dos } \\
\text { turistas }\end{array}$ \\
\hline & & $\begin{array}{l}\text { Medida em que os resultados da investigação são integrados } \\
\text { em planejamento turístico e desenvolvimento }\end{array}$ \\
\hline & $\begin{array}{c}\text { Desenvolvimento } \\
\text { de Recursos } \\
\text { Humanos }\end{array}$ & $\begin{array}{l}\text { Qualidade dos programas de turismo / hospitalidade / } \\
\text { treinamento de formação }\end{array}$ \\
\hline
\end{tabular}


Continuação...

\begin{tabular}{|c|c|c|}
\hline & & $\begin{array}{l}\text { Nível de rivalidade competitiva entre as empresas (turismo } \\
\text { interno) }\end{array}$ \\
\hline & & Nível de cooperação entre as empresas do destino \\
\hline & $\begin{array}{c}\text { Entorno } \\
\text { Competitivo }\end{array}$ & $\begin{array}{l}\text { Vínculo entre as empresas de turismo e hotelaria e de outras } \\
\text { empresas }\end{array}$ \\
\hline & & Qualidades empreendedoras dos agentes de turismo local \\
\hline & & Acesso ao capital de risco \\
\hline & & Ética entre as empresas de turismo \\
\hline & & $\begin{array}{l}\text { Empresas utilizam a tecnologia para garantir a vantagem } \\
\text { competitiva }\end{array}$ \\
\hline & & Proximidade de outros destinos \\
\hline & Localização do & Distância do maior mercado emissor \\
\hline & Destino & Tempo de viagem a partir do maior mercado emissor \\
\hline & & Contexto global dos negócios \\
\hline & & Estabilidade política \\
\hline & & Meio legal e regulatório \\
\hline & Entorno Global & Políticas governamentais para o desenvolvimento do turismo \\
\hline & (macro) & Condições econômicas dos mercados de origem \\
\hline & & Meio sociocultural \\
\hline & & Investimentos para o desenvolvimento do turismo \\
\hline & & Mudanças tecnológicas \\
\hline & & Relação qualidade-preço do destino turístico \\
\hline & & Taxas de cambio \\
\hline & $\begin{array}{c}\text { Preço } \\
\text { Competitivo }\end{array}$ & $\begin{array}{l}\text { Preços das passagens de avião dos principais mercados de } \\
\text { origem }\end{array}$ \\
\hline & & Preços das hospedagens \\
\hline & & Preços dos pacotes turísticos \\
\hline & & Preço da viagem em relação aos destinos concorrentes \\
\hline & Segurança & Nível de segurança do turista no destino \\
\hline & & Incidência de crime contra o turista no destino \\
\hline & Índice de & Índice agregado pela competitividade de preços \\
\hline & Competitividade & Por propósito de viagem \\
\hline & de Preços & Por setor de turismo \\
\hline & & Orçamento do Ministério do Turismo \\
\hline Indicadores de & & Orçamento da OMT \\
\hline Rendimento de Mercado & Apoio & $\begin{array}{l}\text { Gasto com o marketing do destino (comparação com os } \\
\text { concorrentes) }\end{array}$ \\
\hline & Governamental & Apoio à indústria de transportes \\
\hline & ao turismo & Programas industriais pelo acesso da indústria do turismo \\
\hline & & Benefícios Fiscais \\
\hline & & Subsídios da indústria \\
\hline & & Assistência na comercialização de exportações \\
\hline & & $\begin{array}{l}\text { Habilidades profissionais de educação - Treinamento para o } \\
\text { turismo }\end{array}$ \\
\hline
\end{tabular}

Fonte: Dwyer; Kim, 2003; Fgv; Mtur; Sebrae, 2014.

Elaboração: os autores, 2015.

O Estudo dos 65 Destinos Indutores não apresenta relação no determinante recursos criados com os itens relacionados à qualidade; no determinante fatores de apoio em relação a itens relacionados à qualidade, hospitalidade e relação com o mercado; no determinante recursos herdados nos itens relacionados à artes 
tradicionais, variedade gastronômica e cultura local; no determinante gestão do destino itens em relação à eficácia, supervisão, visão do destino, qualidade dos programas e políticas públicas de turismo; no determinante condição situacional se configura a maior parte dos indicadores que não aparecem no estudo brasileiro, itens relacionados ao entorno competitivo, preço, segurança e localização; e no determinante indicadores de rendimento de mercado itens relacionados aos preços e apoio governamental.

Nos dois modelos apresentados, ao se estabelecer indicadores de competitividade se determinam aspectos que estão diretamente relacionados ao desenvolvimento do destino turístico, onde a competitividade é um conceito que vem assumindo um papel de destaque no planejamento e na gestão do destino (BUHALIS, 2000; TABERNER, 2007).

\section{CONSIDERAÇÕES FINAIS}

Fundamentalmente, a competitividade de destinos turísticos é um fenômeno que está intimamente ligado às noções de concorrência do mercado, portanto pode ser entendida como sendo uma conformação entre as estratégias, interna e externa, assumida por uma região/país. O conceito de competitividade está ainda, associado a uma visão teórica do processo econômico e produtivo, apresentando dificuldade em sua mensuração. A importância que o setor turístico tem representado para a economia dos países acirrou a competição entre os destinos turísticos. Assim, todo o processo de avaliação da competitividade dos destinos em relação ao turismo pode contribuir no planejamento, gestão e priorização de ações que beneficiarão o setor.

Ao refletir sobre os dados compilados observa-se que a competitividade é uma temática relevante, por isso buscou-se neste estudo, comparar o Modelo de Competitividade de Dwyer e Kim (2003), com o Estudo de Competitividade dos 65 Destinos Indutores (FGV; MTUR; SEBRAE, 2014).

O Modelo de Competitividade de Dwyer e Kim (2003) e o Estudo dos 65 Destinos Indutores citados acima abordam a temática da competitividade de destinos turísticos. Ambos apresentam uma relação direta com as temáticas de sustentabilidade e marketing, porém o modelo de Dwyer e Kim (2003) enfatiza a qualidade frente a 
diversos indicadores dentro do modelo, enquanto que no estudo brasileiro não se o apresenta como uma categoria/dimensão específica apenas o considera no contexto geral.

Abordar um programa público como o Estudo de Competitividade dos 65 Destinos Indutores, que possui 13 dimensões, entre elas: econômicas, sociais, culturais e ambientais é um processo complexo. O estudo se concentra em identificar e relacionar cada dimensão, para avaliar a competitividade. Deve-se destacar que o Estudo dos 65 Destinos Indutores foi planejado, organizado e estruturado com o foco na realidade dos municípios brasileiros, portanto, em uma perspectiva customizada.

Por outro lado, o Modelo de Dwyer e Kim (2003) é mais específico em vários indicadores que relacionam qualidade e eficiência, porém de difícil aplicação, por dois motivos considerados claros: a quantidade de indicadores, e que nem todo destino/região possui todas essas informações relacionadas ou catalogadas. Pode-se afirmar ainda que este modelo de competitividade de destinos turísticos apresenta o diferencial da qualidade como fator importante e decisivo de planejamento e gestão no desenvolvimento sustentável do destino como um todo.

A literatura indica que a vantagem competitiva no setor turístico é alcançada a partir do momento que um destino turístico oferece uma experiência turística superior em relação a outro destino, considerando os turistas potenciais desses destinos (DWYER; KIM, 2003).

Middleton e Hawkins (1998), Bramwell e Lane (1993) defendem um planejamento integral de um destino turístico, com uma visão de longo prazo e priorizando ações coordenadas. A partir disso, um marketing de destinos turísticos que seja simultaneamente orientado pelo produto e pelo mercado (product-oriented; marketoriented) torna-se primordial. Neste sentido, o planejamento, o marketing integrado dos destinos facilita a gestão, maximizando os benefícios do desenvolvimento turístico e minimizando seus impactos negativos (KASTENHOLZ, 2004, 2006; MIDDLETON; HAWKINS, 1998). Onde o maior desafio dos gestores de um destino turístico é unir parceiros e empresas em conjunto para competir ao invés de cooperar e dessa forma, reunir recursos para o desenvolvimento de um marketing mix completo (BUHALIS, 2000, BUHALIS; COOPER, 1998). 
Neste panorama, a competitividade e o crescimento tornaram-se questões de efetiva importância no debate mundial sobre o papel do turismo como instrumento de desenvolvimento econômico (FERNÁNDEZ; RIVERO, 2010). Assim, os gestores dos destinos turísticos enfrentam um difícil processo de sobrevivência, onde a estratégia competitiva marca e define suas trajetórias (SANCHO PÉREZ; GARCÍA MESANAT, 2007). Pode-se afirmar, portanto que em ambos: no modelo de competitividade de Dwyer e Kim e no Estudo de Competitividade dos 65 Destinos Indutores se consideram aspectos referentes às temáticas de qualidade, marketing e sustentabilidade importantes para o desenvolvimento da competitividade, porém em diferentes graus de importância, fato que se evidencia pelo número de indicadores relacionados a cada um destes constructos.

Observa-se que ainda há uma enorme frente de trabalho em relação à competitividade de destinos turísticos, tanto em termos de conhecimento científico quanto em sua aplicação na prática no processo de gerenciamento de destino, o que sugere a exploração destes temas de pesquisas para futuros estudos.

\section{REFERÊNCIAS}

ALONSO FERRERAS, V. Factores Criticos de Éxito y Evaluación de la Competitividad de Destinos Turísticos. Estudios y Perspectivas en Turismo, v. 19, p. 201-220, 2010.

ANDRADES-CALDITO, L.; SÁNCHEZ-RIVERO, M.; PULIDO-FERNÁNDEZ, J. I. Differentiating Competitiveness through Tourism Image Assessment an Application to Andalusia (Spain). Journal of Travel Research, v. 52, n. 1, p. 68-81, 2013.

BRAMWELL, W.; LANE, B. Sustainable Tourism: An Evolving Global Approach. Journal of Sustainable Tourism, v. 1, n. 1, p. 1-5, 1993.

BUHALIS, D.; COOPER, C. Competition or co-operation: The needs of Small and Medium sized Tourism Enterprises at a destination level. In: LAWS, E.; FAULKNER, B.; MOSCARDO, G. (ed.) Embracing and managing change in Tourism. Londres: Routledge, 1998.

BUHALIS, D. Marketing the competitive destination of the future. Tourism Management, v. 21, n. 1, p. 97-116, 2000. 
COSTA, H. Análise das relações de rede e do perfil da competitividade turística: estudo comparativo entre São Francisco do Sul e Laguna-SC. Dissertação (Mestrado, em Turismo e Hotelaria), Univali, Balneário Camboriú, 2005.

CROUCH, G. I.; RITCHIE, J. R. B. Tourism, Competitiveness and Societal Prosperity. Journal of Business Research, v. 44, n. 3, p. 137-152, 1999.

CHIM-MIKI, A. F.; GANDARA, J. M. G.; MEDINA-MUÑOZ, D. R. O estado atual de pesquisas sobre competitividade turística no Brasil. Caderno Virtual de Turismo. Rio de Janeiro, v. 12, n. 2, p. 212- 223, 2012.

DAVIDSON, T. L. O que são viagens e turismo: constituem de fato um setor? In: Theobald, W. F. (org.). Turismo Global. Tradução Anna Maria Capovilla, Maria Cristina Guimarães Cupertino, João Ricardo Barros Penteado. São Paulo: Editora SENAC São Paulo, 2001.

DOMARESKI, T. C. A Competitividade das Destinações Turísticas: O Caso de Foz do Iguaçu (Pr), Brasil. Dissertação (Mestrado em Turismo e Hotelaria), Universidade do Vale do Itajaí, Balneário Camboriú, 2011.

DWYER, L.; KIM, C. Destination Competitiveness: Determinants and Indicators. Current Issues in Tourism, v. 6, n. 5, p. 369-414, 2003.

EMBRATUR, Pesquisa Anual de Conjuntura Econômica. Disponível em: http://www.turismo.gov.br, 2010. Acesso em: 02/05/2014.

FERNÁNDEZ, J. I. P.; RIVERO, M. S. Competitividad versus crecimiento en destinos turísticos. Un análisis mediante técnicas multivariantes. Cuadernos de Economia, v. 33 n. 91, p. 159-181, 2010.

FGV; MTUR; SEBRAE. Relatório Brasil: estudo de competitividade dos 65 destinos indutores do desenvolvimento turístico regional. Brasília: MTur, 2014.

GÂNDARA, J. M. G. La Imagen de Calidad Ambiental Urbana como Recurso Turístico: El Caso de Curitiba, Brasil. Tese (Doutorado em Turismo e Desenvolvimento Sustentável), Universidad de Las Palmas de Gran Canária, Espanha, 2001.

GÂNDARA, J. M. G. La Calidad y La Competividad de los destinos turísticos urbanos. Turismo Visão e Ação, v. 6, p. 69-93, 2004.

.; CHIQUIM, C. E.; PALUMBO, G.; LAGO, H. Planejamento estratégico participativo para construir o destino turístico de Foz do Iguaçu - PR. El Periplo Sustentable. Cidade do México, v. 1, n. 12, p. 185 - 235, 2007.

GÂNDARA, J. M. G.; CHIM-MIKI, A.; DOMARESKI-RUIZ, T. C.; BIZ, A. A. La Competitividad Turística de Foz do Iguaçu Según los Determinantes Del Integrative 
Model de Dwyer \& Kim: Analizando la estratégia de construcción del futuro. Cuadernos de Turismo, n. 31, p. 105-128, 2013.

GO, F. M.; GOVERS, R. Integrated quality management for tourist destinations: a European perspective on achieving competitiveness. Tourism Management, v. 21, p. 79-88, 2000.

HASSAN, S. Determinants of Markets Competitiveness in an Environmentally Sustainable Tourism Industry. Journal of Tourism Research, v. 38, p. 239-245, 2000.

HU, W.; WALL, G. Environmental Management, Environmental Image and the Competitive Tourist Attraction. Journal of Sustainable Tourism, v. 13, n. 6, p. 617$635,2005$.

INSKEEP E. Tourism planning: An integrated and sustainable development approach. New York: Van Nostrand Reinhold, 1991.

IRVING, M. A.; BURSZTYN, I.; SANCHO, A.; MELO, G. Revisitando significados em sustentabilidade no planejamento turístico. Caderno Virtual de Turismo, v. 5, n. 4, p. 1-7, 2005.

KASTENHOLZ, E. "Management of demand" as a tool in sustainable tourist destination development. Journal of Sustainable Tourism, n. 12, v. 5, p. 388-408, 2004.

KASTENHOLZ, E. O marketing de destinos turísticos - O seu significado e potencial, ilustrado para um destino rural. Revista de Turismo e Desenvolvimento, n. 6, p. 31-44, 2006.

KRIPPENDORF, J. Les Devoreurs de Paysages. Lausanne: Heures, 1977.

Publications, 1980.

Content analysis: an introduction to its methodology. London: Sage

LAVILlE, C.; DIONNE, J. A construção do saber: manual de metodologia da pesquisa em ciências humanas. Porto Alegre: Artmed; Belo Horizonte: UFMG, 1999.

MAZARO, R. M.; VARZIN, G. Modelos de competitividad para destinos turísticos en el marco de la sostenibilidad. Revista de Administração Contemporânea, v. 12, n. 3, p. 789-809, 2008.

MIDDLETON, V.; HAWKINS R. Sustainable tourism: a marketing perspective. Oxford: Butterworth Heinemann, 1998.

MIHALIC, T. Environmental management of a tourist destination - A factor of tourism competitiveness. Tourism Management, v. 21, p. 65-78, 2000.

PORTER, M. Vantagem Competitiva. 18 ed. Rio de Janeiro: Campus, 1989. 
RITCHIE, J. R. B.; CROUCH, G. I. The Competitive Destination: a sustainability perspective. Tourism Management, v. 21, n. 1, p. 1-7, 2000.

RITCHIE, J. R. B.; CROUCH, G. I. The Competitive Destination: A Sustainable Tourism Perspective, CABI Publishing, Wallingford, UK, 2003.

SANCHO PÉREZ, A.; GARCÍA MESANAT, G. El posicionamiento de un destino turístico en un mercado globalizado y competitivo: comparación de prácticas entre competidores líderes, 2007. Disponível em:

<http://www.uv.es/ sancho/benchmarking.pdf $>$.

SANTOS, S. R. dos S.; TEIXEIRA, M. G. C. Análise do Plano de Desenvolvimento Turístico no Estado do Maranhão: potencialidades e entraves na gestão de Pólo Turístico em município estratégico. In: EnANPAD, 2008, Rio de Janeiro. Anais do XXXII Encontro da ANPAD, Rio de Janeiro, 2008.

SOUZA, M. L. ABC do desenvolvimento urbano. 2. ed. RJ: Bertrand, 2005.

TABERNER, J. G. Measuring destination competitiveness: an exploratory study of the Canaries, mainland Spain, France, the Balearics and Italy. Tourism Today, n.7, p. 6178, 2007.

VIEIRA, D. P. Investimentos, Competitividade e Desenvolvimento em Destinos Indutores do Turismo Brasileiro. Dissertação (Mestrado em Administração), Universidade de Brasília, 2013.

ZEITHAML, V. A.; BITNER, M. J.; GREMLER, D.D. Marketing de Serviços: a empresa com foco no cliente. Porto Alegre: Bookman, 2003.

Recebido em: 11-11-2013.

Aprovado em: 11-12-2013. 